\title{
The impacts of knowledge, risk perception, emotion and information on citizens' protective behaviors during the outbreak of COVID-19: a cross-sectional study in China
}

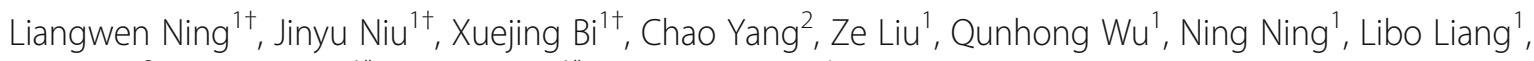
Aishu Liu ${ }^{3}$, Yanhua Hao ${ }^{1 *}$, Lijun Gao ${ }^{1 *}$ and Chaojie Liu ${ }^{4}$

\begin{abstract}
Background: Individual protective behaviors play an important role in the control of the spread of infectious diseases. This study aimed to investigate the adoption of protective behaviors by Chinese citizens amid the COVID19 outbreak and its associated factors.

Methods: An online cross-sectional survey was conducted from 22 January to 14 February 2020 through Wenjuanxing platform, measuring their knowledge, risk perception, negative emotion, response to official communication, and protective behaviors in relation to COVID-19. A total of 3008 people completed the questionnaire, of which 2845 were valid questionnaires.
\end{abstract}

Results: On average, $71 \%$ of respondents embraced protective behaviors. Those who made no error in the knowledge test $(A O R=1.77, p<0.001)$ perceived the high severity of the epidemic (AOR $=1.90, p<0.001)$, had high negative emotion $(A O R=1.36, p=0.005)$, reported good health $(A O R=1.94, p<0.001)$, paid high attention to the governmental media ( $A O R=4.16, p<0.001)$ and trusted the governmental media ( $A O R=1.97, p<0.001$ ) were more likely to embrace protective behaviors after adjustments for variations in potential confounding factors. Women and older people were also more likely to embrace protective behaviors. No regional or educational differences were found in the adoption of protective behaviors.

Conclusion: The majority of Chinese citizens embraced protective behaviors. Higher levels of protective behaviors are associated with higher knowledge, perceived severity, negative emotion, and attention to and trust in the official governmental media. Official governmental communication is the largest single predictor of protective behaviors.

Keywords: COVID-19, China, Behavior, Public health, Perception

\footnotetext{
*Correspondence: hyhyjw@126.com; gg73@163.com

${ }^{\dagger}$ Liangwen Ning, Jinyu Niu and Xuejing Bi contributed equally to this work.

${ }^{1}$ School of Health Management, Harbin Medical University, Harbin, China

Full list of author information is available at the end of the article
}

(c) The Author(s). 2020 Open Access This article is licensed under a Creative Commons Attribution 4.0 International License, which permits use, sharing, adaptation, distribution and reproduction in any medium or format, as long as you give appropriate credit to the original author(s) and the source, provide a link to the Creative Commons licence, and indicate if changes were made. The images or other third party material in this article are included in the article's Creative Commons licence, unless indicated otherwise in a credit line to the material. If material is not included in the article's Creative Commons licence and your intended use is not permitted by statutory regulation or exceeds the permitted use, you will need to obtain permission directly from the copyright holder. To view a copy of this licence, visit http://creativecommons.org/licenses/by/4.0/ The Creative Commons Public Domain Dedication waiver (http://creativecommons.org/publicdomain/zero/1.0/) applies to the data made available in this article, unless otherwise stated in a credit line to the data. 


\section{Background}

Coronavirus Disease 2019 (COVID-19) is one of the most serious respiratory illnesses caused by the severe acute respiratory syndrome coronavirus 2 (SARS-CoV-2) since the 1918 global influenza pandemic. It has had a profound health and economic impact on the world and shows little sign of containment yet [1]. On 30 January 2020, the World Health Organization (WHO) declared the COVID-19 outbreak a public health emergency of international concern [2]. The outbreak has not only resulted in a serious death toll, but also triggered a range of social and psychological reactions, imposing immeasurable consequences on society.

Non-pharmaceutical interventions have been regarded as the most effective measures to end the pandemic in the absence of an effective vaccine and medical treatment at the moment, which require the public to adopt protective behaviors $[3,4]$. These include preventive measures (such as social distancing, hand hygiene, and wearing face masks), avoidance measures (such as home isolation and quarantine and travel restriction), and illness management measures (such as medical consultation, testing, and infection control) [5]. Studies have also shown that these measures can have the positive psychological effect and protect mental health [6-8]. These measures are particularly important and challenging in densely populated communities [9]. The WHO encourages everybody to take responsibility and adopt protective behaviors [10]. But each country may weigh these measures differently taking into consideration the social and cultural context of the country. While social distancing and hand hygiene have been widely accepted as the most important strategies to control the outbreak of COVID-19 [1], the effectiveness of wearing masks by the public has attracted some debate [11]. Empirical evidence shows that restricting crowd gathering in public places can reduce influenza infection by $23 \%$ [12]. Hand hygiene practices were also proved to be equally effective in reducing the transmission of SARS-CoV, another virus from the coronavirus family [13]. Most Asian countries, including China, have encouraged the public to wear face masks in public places from the very beginning of the battle against COVID-19. But it has been endorsed only recently by the US and some European countries.

Success or otherwise of the non-pharmaceutical interventions depends largely on the acceptance of the public, although some measures can be made compulsory by law [5]. The unprecedented lockdown measures taken by the Chinese government stunned the world. Researchers tend to attribute China's success in the control over the outbreak of COVID-19 to such strong governmental actions [14]. But limited attention has been paid to public responses to the government's actions. Understanding how the public behaves is critical for the government to develop effective communication strategies and ensure high compliance to protective behaviors. However, there is a dearth of literature documenting the protective behaviors of Chinese citizens amid the outbreak of COVID-19. In this study, we selected the items of protective behaviors based on the Guidelines for the Prevention and Control of COVID-19 issued by the Chinese Centers for Disease Control and Prevention. The guidelines clearly recommend that the public should gather less, wear masks when going out and so on. Previous studies on public knowledge and attitudes toward the outbreak of infectious diseases were usually conducted over the recovery stage [15]. It is important to note that both governmental policies and behaviors of the public are likely to vary and change over time depending on the situation of the epidemic. This study aimed to fill the gap in the literature by assessing the protective behaviors adopted by citizens in China during the middle of the outbreak of COVID-19. The study also explored the determinants of the protective behaviors based on the knowledge-attitudes-practices (KAP) model.

\section{Methods \\ Study setting}

A cross-sectional questionnaire survey of citizens in China over the period from 22 January to 14 February 2020 was conducted when the epicenter Wuhan was placed in complete lockdown. During this period, all provinces launched a category one emergency response, the harshest response designed to control the most serious public health events such as plague and anthrax. In China, public health emergency responses are classified into four levels ranging from the most restrictive to the least restrictive. A category one response involves the strictest measures, including travel restrictions, bans on public events and gatherings, the closure of schools/universities and non-essential services, and isolation and quarantine requirements. The provinces in which a category one response was declared have to follow commands and control from the central government. The four-level system also envisages a gradual staggering of relaxed measures over the recovery period. Local governments regain higher levels of autonomy when emergency responses are downgraded.

\section{Study participants}

Adults over the age of 18 years in China were eligible to participate in this study. The survey was voluntary and anonymous. The return of completed questionnaire was deemed as informed consent. 


\section{Data collection}

The questionnaire survey was conducted online, the only available avenue for data collection at the time. An online survey has the advantage of reaching a large audience rapidly at the cost of bias toward those who have access to the online platform [16]. The study used Wenjuanxing, a widely accepted online questionnaire survey platform in China for data collection.

This research uses the sample service function of the Wenjuanxing platform. The platform has a large number of potential sample population to ensure the randomness of sampling and the reliability of inferences. We require the platform to invite respondents of different age groups and places of citizens to participate the survey to ensure the sample better representative.

The survey started with an explanation of the purpose and protocol of the study. Participants had to read and confirm their agreement with the statement before proceeding to the questionnaire. They could withdraw at any time whilst completing the questionnaire. Only those surveys without any missing answers could be submitted. Each respondent was allowed to submit one questionnaire only, according to the IP address recorded by Wenjuanxing.

A total of 5579 people accessed the online survey and 3008 (53.9\%) completed the questionnaire. The research team performed a logic check on the returned questionnaires and excluded 163 containing logic errors, which resulted in a final sample size of 2845 (94.5\% of the returned questionnaires) for data analyses.

\section{Measurements}

The survey was guided by the theories of the Social Amplification of Risk Framework (SARF) [17] and the Knowledge, Attitude and Practices (KAP) behavioral model [18], measuring five constructs: knowledge, risk perception, negative emotion, official communication, and protective behaviors in relation to COVID-19. (Additional file 1). The questionnaire items were either derived from the WHO guidelines [19] or adapted from the existing measurement scales [20]. The questionnaire also captured the sociodemographic characteristics of the respondents. The language of the survey is Chinese.

\section{Knowledge}

Appropriate knowledge is a prerequisite condition for the public to take action [21]. A lack of understanding is a major obstacle to public compliance with emergency response measures [9]. According to the KAP model, changes in human behavior occur in three stages: knowledge acquisition, belief generation, and behavior formation [18]. Appropriate knowledge not only encourages the public to take action, but also facilitates the right action. Empirical evidence on the importance of knowledge in the prevention and control of infectious diseases has been found in many countries [22] across a range of diseases including COVID-19. This survey contained 11 knowledge questions, asking what COVID-19 is (e.g. is it a kind of influenza), what symptoms are associated with it (e.g. fatigue, dry cough, fever, difficulty in breathing), how it is transmitted (e.g. through droplets), and how it can be prevented (e.g. hand hygiene, face masks). We did not ask what to do if infected because at the time, it was governmental policy that all infected cases were isolated and treated in hospitals (including makeshift hospitals) in China. The knowledge test questions were aligned with the WHO guidelines. Answers to these questions can be found on the website of the Chinese Centers for Disease Control and Prevention (http://www.chinacdc.cn/jkzt/crb/zl/szkb_11803/) and the National Health Commission of People's Republic of China (http://www.nhc.gov.cn/). During the epidemic, the Chinese government carried out knowledge popularization through television, websites, social media, community advocacy and so on. These intensive publicity has made the Chinese public generally have a high level of knowledge on COVID-19. In order to better distinguish the level of the public's knowledge on COVID19, respondents were categorized into two groups: those who gave correct answers to all of the questions were classified as high level group and the others as relative lower level group.

\section{Risk perception}

Risk perception refers to individual's intuitive risk assessment, reflecting public attitudes or beliefs about potential harm [23]. It is widely accepted that perceived risk is fundamental for triggering behavioral changes [16]. Those who downplay the potential harm of a risk event are less likely to take targeted actions to prevent the event [23]. Risk perception was found to be a predictor of behavioral changes amid the outbreak of H1N1 influenza and SARS $[15,24]$. Risk perception is usually shaped by one's knowledge. Knowledge enables the proper self-assessment of the risk of an event and its associated consequences [25]. Several studies have proved that individuals who perceive a high risk [26] and high severity [27] of the COVID-19 outbreak are most likely to take precautionary action. However, researchers are increasingly concerned about the potential bias of risk perception in the public when high levels of uncertainty remain for COVID-19, a new disease for which our understanding is limited [26]. Biased risk perception can make behavioral decisions deviate from rationality, resulting in serious social and economic consequences [28]. Several broadly applicable scales exist which measure risk perception based on a consensus that risk perception is a multidimensional concept [20]. Most scales 
consider it to be a function of individual affective reaction to the possibility and consequentiality of risks. The $S A R F$ theory extends the dimension to include interactions between individuals and social contexts, incorporating psychological, social and cultural perspectives into the measurement of risk perception [17]. This is because a particular social environment may amplify or attenuate individual responses to the risk or risk event. The risk perception scale we used in this study is introduced from "Public Risk Perception Scale for Public Health Emergencies" we developed in 2018. The scale has gone through a rigorous development process and has been published in the Chinese Journal of Public Health [29]. Reliability and validity analysis results show that the scale has good reliability (Cronbach's $\alpha=0.75$ ) and validity $(\mathrm{GFI}=0.982$, AGFI $=0.963$, IFI $=0.947, \mathrm{TLI}=0.914$, RMSEA $=0.059)$. Expert consultations and pilot survey were carried out to ensure the quality of the questionnaire. In this study, three components of risk perception were measured, namely susceptibility (3 items), severity (4 items), and controllability ( 2 items). Example questions include "I am very likely to be infected" (susceptibility); "The spread of COVID-19 is very wide" (severity); "It is difficult to treat" (controllability). Study participants were asked to rate each question on a fivepoint Likert scale ranging from 1 "strongly disagree" to 5 "strongly agree". A summed average score for each component was calculated. A score above 3 was deemed as high in risk perception.

\section{Emotional response}

High levels of mental health problems have been observed in China during the COVID-19 outbreak accompanied by prolonged social isolation [7]. Fear of COVID19 is believed to be one of the central factors elevating the level of stress and anxiety [30]. Although fear is a negative emotional response, it may exacerbate perceived risks [31], stimulating protective behaviors [32]. Fear has long been recognized to have an "inverted $U$ shaped drive function" [33]. It can prompt individuals to solve the problem or avoid the problem [34]. Fear may increase people's alertness to potential risks, triggering a stronger willingness to avoid the risk. But if a negative emotional response lasts too strong, it can also prevent people from engaging in certain protective behaviors [35]. Measuring the emotional responses of people in social isolation during the COVID-19 outbreak has started to attract attention from the research community [7]. But unfortunately, no valid scale was available when we collected the data. In this study, we designed three items measuring fear (I am afraid that I or my family will be infected with COVID-19), worry (I am very worried when I know someone who is coming back from or going to Wuhan), and psychological tension (I am very nervous about the epidemic). Study participants were asked to rate their emotional response on a five-point Likert scale ranging from 1 "strongly disagree" to 5 "strongly agree". A summed average score above 3 was deemed as high in negative emotional responses.

\section{Official communication}

Information communication is critical for the public to obtain knowledge and comply with or defy governmental advice. Balkhy et al. [36] found that public attention to the media played an essential role in the control of swine flu in Saudi Arabia through behavioral changes. Public media provides a platform for individuals to interact with the broader society, which can shape their attitudes toward governmental policies. Media use has a profound impact on knowledge acquisition at a time of crisis [37], especially when the entire society is virtually locked down. Meanwhile, media reports can also fuel fear [38]. Modern information technology has broadened the source of information dramatically. While it enables easy and rapid access to information, the increased diversity of information also brings great challenges to government communications with the public. In a public health crisis like COVID-19, consistency in information communications is critical. In some countries, governments have been frustrated with the media [39]. Indeed, trust plays a critical role in the public acceptance of government messages. Under a high level of uncertainty due to limited knowledge, the public are likely to simply follow the agencies they trust [40]. In this study, we measured public attention to and trust in the official governmental media in relation to COVID-19. Study participants were asked to rate their experience on a five-point Likert scale ranging from 1 "never" to 5 "always". A score above 3 was deemed as high in attention or trust.

\section{Protective behaviors}

The protective behaviors assessed in this study were drawn from the research of Bish [5] and the guidelines issued by the Chinese government. These included avoiding crowds, wearing face masks, keeping good indoor airflow, maintaining overall health, following official guidelines, encouraging behavioral compliance of other people, preventing spread of the virus to others, practicing good hand hygiene, and avoiding contact with wild animals. Study participants were asked to rate their behaviors on a five-point Likert scale ranging from 1 "never" to 5 "always". A summed average score was calculated, with a score above 3 indicating a high level of embracement of protective behaviors.

The sociodemographic data captured in this study included location, residency (urban vs rural), gender, age, marital status, educational attainments, perceived health, and vulnerability of family members to COVID-19. 
Previous studies showed that these sociodemographic characteristics are associated with public knowledge and protective behaviors in relation to various infectious diseases [5]. According to the official reports, Hubei (with Wuhan as capital city), Guangdong, Zhejiang, Henan, Hunan, Anhui, Jiangxi and Chongqing were considered high-risk areas in China. By 14 February, 61,475 cases and 1486 deaths were reported in the high-risk areas, compared with a total of 5101 cases and 38 deaths in other regions in China. Pregnant women, the elderly ( $\geq 65$ years) and children ( $\leq 5$ years) were commonly considered as the vulnerable populations, deserving extra protection from society [41]. In this study, self-reported health was rated on a five-point Likert scale ranging from 1 (very poor) to 5 (very good).

\section{Statistical analysis}

The characteristics of the study participants were described through frequency analyses and the respondents from high-risk areas were compared with those from other regions using Chi-square tests.

The percentage of correct answers given to the knowledge questions was calculated for each item and all items combined, respectively. Knowledge differences between the respondents from high-risk areas and other regions were compared using Chi-square tests.

The mean value and standard deviation (SD) of the average summed score for each risk perception component and the protective behaviors were calculated and compared between the respondents from high-risk areas and other regions using student $t$ tests.

The participants were categorized into two groups: those who had a summed average score above 3 in protective behaviors (highly protective) and those who did not. Logistic regression models were established to determine the predictors of the protective behaviors. Variables in relation to the sociodemographic characteristics of the participants and their self-ratings on knowledge, risk perception, negative emotion, and official communication were entered into the regression models using an enter approach.

To test the robustness of the findings of the logistic regression model, a linear regression model was established with the protective behavior scores being treated as a continuous variable. Partial least squares structural equation modeling (SEM) analyses were performed to verify the theoretical hypotheses that guided the selection of the measurements in this study. In the SEM, knowledge, risk perception and official communication were treated as formative measurements while emotional response and protective behaviors were treated as reflective measurement [42]. The SEM results supported all of the theoretical hypotheses (Additional File 2).
All analyses in this study were performed using SPSS/ Win and SmartPLS. A $p$ value of less than 0.05 was considered statistically significant.

\section{Results}

\section{Demographic characteristics of respondents}

Urban citizens accounted for $48.6 \%$ of the study sample. About $32.2 \%$ lived in the high-risk areas. The majority of respondents were female (58.2\%) and single (54.0\%). Most were younger than 40 years $(85.6 \%)$, had a university degree (69.1\%), lived with a vulnerable family member $(71.4 \%)$, and reported good health (73\%). The respondents from the high-risk areas were younger and more likely to be male and resided in rural areas compared with those from other regions (Table 1).

\section{COVID-19 knowledge of respondents}

The percentage of correct answers given to the 11 questions ranged from 54.1 to $97.6 \%$ (Table 2). On average, the respondents gave a correction answer to 9.7 (SD = 1.46) questions. About $34.5 \%$ answered all of the questions correctly. More than $90 \%$ of respondents understood the symptoms of COVID-19 and its transmission routes and preventive measures. No differences in knowledge between those from the high-risk areas and other regions were found (Table 2).

\section{Risk perception of respondents}

A high level of the perceived severity of the COVID-19 outbreak was found, with $94.4 \%$ respondents giving a rating higher than 3 out of a possible score of 5 . Slightly more than half $(58.2 \%)$ of the respondents weren't optimistic (with a score $>3$ ) about the controllability of the outbreak. There was a relatively low perception of susceptibility, with only $29.2 \%$ respondents giving a rating higher than 3 out of a possible score of 5 . No differences in perceived controllability were found between those from the high-risk areas and other regions. But the respondents from the high-risk areas had higher scores in perceived susceptibility and severity compared with their counterparts from other regions (Table 3).

\section{Protective behaviors}

Overall, $71.0 \%$ of respondents obtained a summed average behavior score above 3, indicating a high level of embracement of protective behaviors. Relatively higher levels of actions for protecting others (e.g. stay away from others if ill) and compliance with official advice were found, compared with the measures of protecting oneself such as hand hygiene and health maintenance. The respondents from high-risk areas were more likely to avoid crowds than those from other regions. But the respondents outside the high-risk areas appeared to be 
Table 1 Sociodemographic Characteristics of Respondents

\begin{tabular}{|c|c|c|c|c|c|c|c|}
\hline \multirow[t]{2}{*}{ Characteristics } & \multicolumn{2}{|l|}{ Total } & \multicolumn{2}{|c|}{ High-Risk Areas } & \multicolumn{2}{|c|}{ Other Regions } & \multirow[t]{2}{*}{$p$} \\
\hline & $n=2845$ & $\%$ & $n=915$ & $\%$ & $n=1930$ & $\%$ & \\
\hline Residency & & & & & & & $<0.001$ \\
\hline Rural & 1462 & 51.4 & 579 & 63.3 & 883 & 45.8 & \\
\hline Urban & 1383 & 48.6 & 336 & 39.6 & 1047 & 54.2 & \\
\hline Gender & & & & & & & 0.028 \\
\hline Male & 1188 & 41.8 & 409 & 44.7 & 779 & 40.4 & \\
\hline Female & 1657 & 58.2 & 506 & 55.3 & 1151 & 59.6 & \\
\hline Age (years) & & & & & & & $<0.001$ \\
\hline$<25$ & 1204 & 42.3 & 399 & 43.6 & 805 & 41.7 & \\
\hline $25-40$ & 1233 & 43.3 & 419 & 45.8 & 814 & 42.2 & \\
\hline$>40$ & 408 & 14.3 & 97 & 10.6 & 311 & 16.1 & \\
\hline Education & & & & & & & $<0.001$ \\
\hline No university degree & 879 & 30.9 & 337 & 36.8 & 542 & 28.1 & \\
\hline University degree & 1966 & 69.1 & 578 & 63.2 & 1388 & 71.9 & \\
\hline Marital status & & & & & & & 0.189 \\
\hline Not married & 1535 & 54.0 & 510 & 55.7 & 1025 & 53.1 & \\
\hline Married & 1310 & 46.0 & 405 & 44.3 & 905 & 46.9 & \\
\hline Living with vulnerable people & & & & & & & 0.758 \\
\hline No & 813 & 28.6 & 258 & 28.2 & 555 & 28.8 & \\
\hline Yes & 2032 & 71.4 & 657 & 71.8 & 1375 & 71.2 & \\
\hline Self-reported health & & & & & & & 0.351 \\
\hline Poor & 769 & 27.0 & 237 & 25.9 & 532 & 27.6 & \\
\hline Good & 1073 & 73.0 & 678 & 74.1 & 1398 & 72.4 & \\
\hline
\end{tabular}

Table 2 COVID-19 knowledge of respondents

\begin{tabular}{|c|c|c|c|c|c|c|c|}
\hline \multirow[t]{3}{*}{ Question } & \multicolumn{6}{|c|}{ Respondents answering questions correctly } & \multirow[t]{3}{*}{$p$} \\
\hline & \multicolumn{2}{|l|}{ Total } & \multicolumn{2}{|c|}{ High-risk Area } & \multicolumn{2}{|c|}{ Other Regions } & \\
\hline & $\bar{n}$ & $\%$ & $\bar{n}$ & $\%$ & $\bar{n}$ & $\%$ & \\
\hline \multicolumn{8}{|l|}{ What is COVID-19? } \\
\hline COVID-19 is different from influenza & 1540 & 54.1 & 474 & 51.8 & 1066 & 55.2 & 0.086 \\
\hline There is no special treatment, but many symptoms can be managed & 2152 & 75.6 & 699 & 76.4 & 1453 & 75.3 & 0.520 \\
\hline \multicolumn{8}{|l|}{ Symptoms of COVID-19? } \\
\hline Generally include fever (some not), fatigue, dry cough, and dyspnea & 2757 & 96.9 & 892 & 97.5 & 1865 & 96.6 & 0.219 \\
\hline Most have mild to moderate symptoms, but a few serious even die & 2185 & 76.8 & 694 & 75.8 & 1491 & 77.3 & 0.406 \\
\hline \multicolumn{8}{|l|}{ Transmission route? } \\
\hline COVID-19 can be transmitted from person to person & 2734 & 96.1 & 882 & 96.4 & 1848 & 95.8 & 0.417 \\
\hline COVID-19 virus can spread through breathing and droplets & 2730 & 96.0 & 880 & 96.2 & 1854 & 96.1 & 0.885 \\
\hline \multicolumn{8}{|l|}{ Preventive measures? } \\
\hline Avoid crowded places & 2721 & 95.6 & 878 & 96.0 & 1843 & 95.5 & 0.571 \\
\hline Wear a face mask in public places & 2728 & 95.9 & 886 & 96.8 & 1842 & 95.4 & 0.081 \\
\hline Wash hands frequently & 2777 & 97.6 & 892 & 97.5 & 1885 & 97.7 & 0.767 \\
\hline Maintain regular ventilation at home & 2638 & 92.7 & 850 & 92.9 & 1788 & 92.6 & 0.808 \\
\hline Early detection, diagnosis, treatment and isolation & 2658 & 93.4 & 856 & 93.6 & 1802 & 93.4 & 0.853 \\
\hline All questions & 982 & 34.5 & 314 & 34.3 & 668 & 34.6 & 0.877 \\
\hline
\end{tabular}


Table 3 Risk Perception of Respondents

\begin{tabular}{|c|c|c|c|c|c|c|c|c|}
\hline \multirow[t]{2}{*}{ Dimension } & \multicolumn{4}{|c|}{ Risk perception scores (Mean \pm SD) } & \multicolumn{4}{|c|}{ Risk perception score > 3 [N (\%)] } \\
\hline & Total & $\begin{array}{l}\text { High-risk } \\
\text { Area }\end{array}$ & $\begin{array}{l}\text { Other } \\
\text { Region }\end{array}$ & $p$ & Total & $\begin{array}{l}\text { High-risk } \\
\text { Area }\end{array}$ & $\begin{array}{l}\text { Other } \\
\text { Region }\end{array}$ & $p$ \\
\hline Susceptibility & $\begin{array}{l}2.76 \pm \\
0.76\end{array}$ & $\begin{array}{l}2.88 \pm \\
0.75\end{array}$ & $\begin{array}{l}2.71 \pm \\
0.76\end{array}$ & $<0.001$ & $830(29.2)$ & $\begin{array}{l}323 \\
(35.3)\end{array}$ & $507(26.3)$ & $<0.001$ \\
\hline I am very likely to be infected & $2.35 \pm 0.98$ & $2.36 \pm 0.98$ & $2.35 \pm 0.98$ & 0.660 & $345(12.1)$ & $113(12.3)$ & $232(12.0)$ & 0.802 \\
\hline $\begin{array}{l}\text { I will be infected if in the same room with a } \\
\text { patient }\end{array}$ & $3.43 \pm 1.11$ & $3.44 \pm 1.11$ & $3.43 \pm 1.11$ & 0.698 & $1543(54.3)$ & $500(54.6)$ & $1043(54.0)$ & 0.763 \\
\hline The epidemic is serious in my community & $2.50 \pm 1.11$ & $2.83 \pm 1.18$ & $2.35 \pm 1.05$ & 0.000 & $527(18.5)$ & $257(28.1)$ & $270(14.0)$ & $<0.001$ \\
\hline Severity & $\begin{array}{l}4.25 \pm \\
0.62\end{array}$ & $\begin{array}{l}4.30 \pm \\
0.59\end{array}$ & $\begin{array}{l}4.23 \pm \\
0.63\end{array}$ & 0.002 & $\begin{array}{l}2685 \\
(94.4)\end{array}$ & $\begin{array}{l}870 \\
(95.1)\end{array}$ & $\begin{array}{l}1815 \\
(94.0)\end{array}$ & 0.260 \\
\hline The spread of COVID-19 is very wide & $4.43 \pm 0.82$ & $4.50 \pm 0.77$ & $4.39 \pm 0.83$ & 0.000 & $2527(88.8)$ & $834(91.1)$ & $1693(87.7)$ & 0.007 \\
\hline The outbreak is very serious & $4.30 \pm 0.82$ & $4.38 \pm 0.78$ & $4.56 \pm 0.69$ & 0.000 & $2456(86.4)$ & $821(89.7)$ & $1635(84.7)$ & $<0.001$ \\
\hline It has high mortality & $4.13 \pm 0.94$ & $4.18 \pm 0.90$ & $4.11 \pm 0.95$ & 0.076 & $2253(79.2)$ & $745(81.4)$ & $1508(78.1)$ & 0.044 \\
\hline Health impact is very serious if infected & $4.15 \pm 0.85$ & $4.16 \pm 0.86$ & $4.15 \pm 0.84$ & 0.789 & $2363(83.1)$ & $767(83.8)$ & $1596(82.7)$ & 0.453 \\
\hline Controllability & $\begin{array}{l}3.37 \pm \\
0.87\end{array}$ & $\begin{array}{l}3.38 \pm \\
0.84\end{array}$ & $\begin{array}{l}3.37 \pm \\
0.89\end{array}$ & 0.717 & $\begin{array}{l}1655 \\
(58.2)\end{array}$ & $\begin{array}{l}551 \\
(60.2)\end{array}$ & $\begin{array}{l}1104 \\
(57.2)\end{array}$ & 0.128 \\
\hline It is difficult to treat & $3.53 \pm 0.96$ & $3.54 \pm 0.96$ & $3.53 \pm 0.97$ & 0.908 & $1642(57.7)$ & $526(57.5)$ & $1116(57.8)$ & 0.865 \\
\hline The spread of COVID-19 is difficult to control & $3.21 \pm 1.09$ & $3.22 \pm 1.06$ & $3.20 \pm 1.10$ & 0.641 & $1209(42.5)$ & $390(42.6)$ & $819(42.4)$ & 0.925 \\
\hline
\end{tabular}

keener to maintain physical health and avoid contact with wild animals (Table 4).

\section{Factors associated with preventative behaviors}

Female and older respondents were more likely to adopt protective behaviors. Those who were married and had a university degree appeared to be more likely to adopt protective behaviors. But the differences became statistically insignificant after adjustments for variations in other variables. Higher levels of knowledge $(\mathrm{AOR}=1.77$, $p<0.001)$ and perceived severity $(\mathrm{AOR}=1.90, p<0.001)$ were associated with higher levels of protective behaviors. Perceived susceptibility and controllability did not show significant associations with protective behaviors. Those who reported good health $(\mathrm{AOR}=1.94, p<0.001)$ and high negative emotion $(\mathrm{AOR}=1.36, p=0.005)$ were more likely to adopt protective behaviors. Attention $(\mathrm{AOR}=4.16, p<0.001)$ to and trust $(\mathrm{AOR}=1.97, p<$ 0.001 ) in official governmental media were proved to be an independent predictor of protective behaviors (Table 5). Similar results were found in the linear regression analyses (Additional File 3).

\section{Discussion}

Overall, the adoption level of protective behaviors in this study population is high and similar to the public responses to previous outbreaks of other infectious diseases. On average, $71 \%$ of respondents obtained a summed average score higher than 3 indicating a high level of embracement of the protective behaviors, with

Table 4 Protective Behaviors of Respondents

\begin{tabular}{|c|c|c|c|c|c|c|c|c|}
\hline \multirow[t]{2}{*}{ Protective Behaviors } & \multicolumn{4}{|c|}{ Mean \pm SD of behavior scores } & \multicolumn{4}{|c|}{ N (\%) with a behavior score $>3$} \\
\hline & Total & $\begin{array}{l}\text { High-risk } \\
\text { areas }\end{array}$ & $\begin{array}{l}\text { Other } \\
\text { Regions }\end{array}$ & $p$ & Total & $\begin{array}{l}\text { High-risk } \\
\text { Areas }\end{array}$ & $\begin{array}{l}\text { Other } \\
\text { Regions }\end{array}$ & $p$ \\
\hline Avoid crowds & $3.97 \pm 1.12$ & $4.05 \pm 1.15$ & $3.93 \pm 1.11$ & 0.005 & $2074(72.9)$ & $703(76.8)$ & $1371(71.0)$ & 0.001 \\
\hline Wear face mask & $3.97 \pm 1.23$ & $4.01 \pm 1.23$ & $3.95 \pm 1.24$ & 0.269 & $2042(71.8)$ & $668(73.0)$ & $1374(71.2)$ & 0.315 \\
\hline Open house windows & $4.01 \pm 1.02$ & $4.03 \pm 1.04$ & $4.01 \pm 1.02$ & 0.644 & $2158(75.9)$ & $699(76.4)$ & $1459(75.6)$ & 0.642 \\
\hline Maintain physical health & $3.77 \pm 1.03$ & $3.71 \pm 1.04$ & $3.79 \pm 1.03$ & 0.037 & $1791(63.0)$ & $556(60.8)$ & $1235(64.0)$ & 0.096 \\
\hline Follow official advices & $4.13 \pm 0.98$ & $4.14 \pm 0.97$ & $4.13 \pm 0.98$ & 0.865 & $2303(80.9)$ & $748(81.7)$ & $1555(80.6)$ & 0.455 \\
\hline Remind family members and friends to take precautions & $4.24 \pm 0.96$ & $4.24 \pm 0.97$ & $4.24 \pm 0.97$ & 0.973 & $2388(83.9)$ & $768(83.9)$ & $1620(83.9)$ & 0.998 \\
\hline Stay away from others if infected & $4.31 \pm 1.02$ & $4.31 \pm 1.02$ & $4.32 \pm 1.01$ & 0.805 & $2389(84.0)$ & $762(83.3)$ & $1627(84.3)$ & 0.488 \\
\hline Wash hands frequently and stop touching face & $4.07 \pm 1.02$ & $4.00 \pm 1.03$ & $4.11 \pm 1.01$ & 0.009 & $2169(76.2)$ & $685(74.9)$ & $1484(76.9)$ & 0.235 \\
\hline Avoid contact with wild animals & $4.47 \pm 1.04$ & $4.44 \pm 1.08$ & $4.50 \pm 1.02$ & 0.143 & $2477(87.1)$ & $778(85.0)$ & $1699(88.0)$ & 0.026 \\
\hline Total & $4.11 \pm 0.77$ & $4.10 \pm 0.76$ & $4.11 \pm 0.77$ & 0.833 & $2021(71.0)$ & $653(71.4)$ & $1368(70.9)$ & 0.790 \\
\hline
\end{tabular}


Table 5 Factors associated with protective behaviors

\begin{tabular}{|c|c|c|c|c|c|c|c|}
\hline \multirow[t]{2}{*}{ Predictor } & \multirow{2}{*}{$\begin{array}{l}\text { Number (\%) of respondents } \\
\text { with a summed average behavior score }>3\end{array}$} & \multicolumn{2}{|c|}{ Unadjusted } & \multicolumn{4}{|c|}{ Adjusted } \\
\hline & & OR & $p$ & $\mathrm{OR}$ & $95 \%$ & ce Interval & $p$ \\
\hline \multicolumn{4}{|l|}{ Gender } & & & & \\
\hline Male (Reference) & $802(67.5)$ & & & & & & \\
\hline Female & $1219(73.6)$ & 1.34 & $<0.001$ & 1.21 & 1.00 & 1.44 & 0.040 \\
\hline Age (years) & & & 0.001 & & & & 0.009 \\
\hline$<25$ (Reference) & $811(67.4)$ & & & & & & \\
\hline $25-40$ & $901(73.1)$ & 1.32 & 0.002 & 1.31 & 1.01 & 1.69 & 0.040 \\
\hline$>40$ & $30(75.7)$ & 1.51 & 0.002 & 1.79 & 1.25 & 2.58 & 0.002 \\
\hline \multicolumn{8}{|l|}{ Education } \\
\hline$<$ University (Reference) & $1424(72.4)$ & & & & & & \\
\hline University & $597(67.9)$ & 1.24 & 0.014 & 1.11 & 0.91 & 1.35 & 0.298 \\
\hline \multicolumn{8}{|l|}{ Marital status } \\
\hline Not married (Reference) & $1043(67.9)$ & & & & & & \\
\hline Married & $978(74.7)$ & 1.39 & $<0.001$ & 1.03 & 0.79 & 1.34 & 0.832 \\
\hline \multicolumn{8}{|l|}{ Area } \\
\hline Other region (Reference) & $1368(70.9)$ & & & & & & \\
\hline High-risk area & $653(71.4)$ & 1.02 & 0.790 & 1.03 & 0.85 & 1.25 & 0.756 \\
\hline \multicolumn{8}{|l|}{ Knowledge } \\
\hline Lower level (Reference) & $1232(66.1)$ & & & & & & \\
\hline High level & $789(80.3)$ & 2.09 & $<0.001$ & 1.77 & 1.46 & 2.15 & $<0.001$ \\
\hline \multicolumn{8}{|l|}{ Perceived susceptibility } \\
\hline$\leq 3$ (Reference) & $1417(70.3)$ & & & & & & \\
\hline > 3 (High) & $604(72.8)$ & 1.13 & 0.191 & 1.01 & 0.73 & 1.38 & 0.966 \\
\hline \multicolumn{8}{|l|}{ Perceived severity } \\
\hline$\leq 3$ (Reference) & $78(48.8)$ & & & & & & \\
\hline$>3$ (High) & $1943(72.4)$ & 2.75 & $<0.001$ & 1.90 & 1.54 & 2.34 & $<0.001$ \\
\hline \multicolumn{8}{|l|}{ Perceived controllability } \\
\hline$\leq 3$ (Reference) & $851(71.5)$ & & & & & & \\
\hline$>3$ (High) & $1170(70.7)$ & 0.96 & 0.635 & 1.03 & 0.85 & 1.24 & 0.769 \\
\hline \multicolumn{8}{|l|}{ Negative emotion } \\
\hline$\leq 3$ (Reference) & $379(62.2)$ & & & & & & \\
\hline$>3$ (High) & $1642(73.4)$ & 1.68 & $<0.001$ & 1.36 & 1.10 & 1.68 & 0.005 \\
\hline \multicolumn{8}{|l|}{ Self-reported health } \\
\hline$\leq 3$ (Reference) & $451(58.6)$ & & & & & & \\
\hline$>3$ (Good) & $1570(75.6)$ & 2.19 & $<0.001$ & 1.94 & 1.61 & 2.34 & $<0.001$ \\
\hline \multicolumn{8}{|l|}{ Information attention } \\
\hline$\leq 3$ (Reference) & $32(20.5)$ & & & & & & \\
\hline$>3$ (High) & $1989(74.0)$ & 3.69 & $<0.001$ & 4.16 & 2.74 & 6.32 & $<0.001$ \\
\hline \multicolumn{8}{|l|}{ Trust in official media } \\
\hline$\leq 3$ (Reference) & $162(49.7)$ & & & & & & \\
\hline$>3$ (High) & $1859(73.8)$ & 2.85 & $<0.001$ & 1.97 & 1.52 & 2.56 & $<0.001$ \\
\hline
\end{tabular}


each item ranging from 63.0\% (maintain physical health) to $87.1 \%$ (avoid contact with wild animals). Understandably, those behaviors that have a limited disruption on daily routines are more likely to be adopted than the others. One of the interesting findings of this study is that the respondents appeared to be quite mindful of the possibility of infecting others. A higher percentage of respondents embraced altruistic behaviors, such as selfisolation when falling ill (84.0\%), following official advice $(80.9 \%)$ and reminding others $(83.9 \%)$, compared with the behaviors of protecting oneself from infection, such as hand hygiene $(76.2 \%)$ and wearing a face mask for self-protection $(71.8 \%)$. But we cannot rule out the possibility of the potential response bias of the study participants. People tend to deny behaviors that can harm others. Despite difficulties in comparing behaviors across populations and studies due to variations in disease contexts and measurement tools, it appears that the adoption level of the protective behaviors in this study population is similar to that of the Hong Kong population during the 2003 SARS epidemic. Lau et al. [43] found that $65-87 \%$ of Hong Kong citizens endorsed hand hygiene, wearing a face mask, and household disinfection guidelines to prevent SARS. But only $24-75 \%$ of Hong Kong citizens tried to avoid crowds, far below the level $(73 \%)$ revealed in this study. This is likely to be a result of lower levels of concern about the potential SARS infection transmitted by asymptomatic carriers. In addition, keeping physical distance in densely-populated cities is always a great challenge. Setbon and colleagues [44] also found that during the 2009 influenza outbreak in France, people were more likely to maintain hand hygiene and avoid contact with patients who had cold symptoms (55-67\%) than the blanket avoidance of crowded places (13-27\%). In comparison with these findings, the level of reported behaviors of crowd avoidance in this study population is deemed relatively high. It was more so in the high-risk areas, perhaps due to the unprecedented harsh lockdown measures taken by the government.

Although knowledge was found to be an independent predictor of protective behaviors, it offers a limited explanation of the level of protective behaviors in the respondents. On average, the study participants gave a correct answer to 9.7 (88\%) questions out of a total of 11. Such a level of knowledge is high, which is consistent with the findings of another study conducted in China [22]. However, the $34.5 \%$ of respondents who answered all of the questions correctly have only slightly higher odds (AOR $=1.77, p<0.001$ ) than the others of adopting the protective behaviors.

Of the three components of risk perception, only perceived severity was found to have a significant association, albeit at a low level (AOR $=1.90, p<0.001)$, with the adoption of protective behaviours. Most respondents considered the outbreak severe $(94.4 \%)$ but close to half of the respondents considered it controllable (41.8\%). But only $29.2 \%$ had a perception of high susceptibility. Kwok [45] found that $89 \%$ citizens in Hong Kong felt susceptible to COVID-19 and 97\% considered the outbreak serious. The low level of perceived susceptibility in this study population may be associated with their young age. This may also explain why the altruistic behaviors were highly appreciated by the study participants. Previous studies showed that a strong perception of the seriousness of a pandemic and its health consequences is an independent predictor of protective behaviors [46]. This was proved to be true during the outbreak of the Middle East Respiratory Syndrome (MERS) and H1N1 flu [46, 47]. Researchers believe that a higher level of risk perception can stimulate anxiety and stress, which encourages the adoption of coping strategies [48]. Those who are more aware of the serious health consequences are more willing to maintain vigilance and take active actions. However, Wachinger et al. [49] noticed that high risk perception is not always associated with high preparedness for natural disasters.

Negative emotion is also an independent predictor of protective behaviors ( $\mathrm{AOR}=1.36, p=0.005$ ). Researchers found that respondents with a moderate level of anxiety were more likely to adopt precautionary measures during the 2003 SARS-CoV epidemic [50]. Wang and Tee found that specific precautionary measures were associated with lower levels of psychological responses during the COVID-19 outbreak [6-8]. According to Harper's study [32], fear had a functional role and was a predictor of positive behavior change. Consistently, our finding suggests that negative emotion was associated with protective behaviors and may help to keep general public safe during COVID-19 pandemic.

Attention to the official governmental media was found to be the largest independent predictor of protective behaviors. The odds of the respondents adopting protective behaviors is 4.16 times greater for those who paid a high-level of attention to the official governmental media than those who paid low attention. This may be a result of the highly "command and control" approach to the control of the COVID-19 outbreak. The Chinese culture is usually characterized by collectivism. Compliance with societal orders is high [51]. Previous studies have also demonstrated the importance of information communication. The impact of information on the cognition and emotion of the public is called by some scholars the exposure effect [52]. It can shape the view of the public, creating a mood of engagement in crisis management.

One of the prerequisite conditions of the exposure effect is the trust of the public in the source of information [53]. Indeed, trust was found to be an independent 
predictor of protective behaviors. The odds of embracing protective behaviors by those who trusted in the official governmental media is almost double those who had low trust in the official governmental media. This result is consistent with the findings of previous research [5]. Menon et al. [54] concluded that transparency, trustfulness, and communication strategies were important measures for the Singaporean government to employ to guide the public to effectively respond to the SARS crisis. In a pandemic such as COVID-19, governments should maintain authenticity in information disclosure, preferably as the sole source of truth. This is particularly important when the public has access to such a wide range of sources of information through social media. Researchers have found that detailed and true health information can effectively curb info-epidemics and gain public trust while outdated health information, wrong information may increase the risk of serious consequences $[55,56]$. Once the public has lost trust in the official governmental media, they are more likely to be misled by false information and produce erroneous risk assessment, resulting in inappropriate behaviors. Slovic [53] points out that trust is fragile and difficult to maintain. Negative events can easily undermine trust. Therefore, the official governmental information has to be open, timely and honest [57].

Consistent with other studies [58], we found that women and older people are more likely to embrace protective behaviors than their male and younger counterparts. Previous studies found that women and older people felt more vulnerable and had a stronger sense of responsibility and willingness to protect society [59]. This study also found that good self-reported health is associated with protective behaviors. But such a link cannot be assumed as causal. The direction of the link may go either way.

\section{Limitations}

This study has some limitations. Although we have used the sample service function to expand the sample ratio of the elderly and rural population, the online survey sample is not representative for the entire population in China. The elderly and those with low levels of education are less likely to have access to the online survey platform than others. Although the study established associations between protective behaviors and knowledge, risk perception and official communication, no casual relationships should be assumed due to the nature of the cross-sectional design. Future research may need to consider the problem of data correction of online survey samples to make it more representative and longitudinal research to explore the relationship between variables.

\section{Conclusion}

The behavioral responses of the public to COVID-19 in China are similar to those of the previous outbreaks of infectious diseases, with the majority embracing protective measures. Higher levels of protective behaviors are associated with high knowledge, perceived severity, negative emotion, and attention to and trust in the official governmental media. Official governmental communication is the largest single predictor of protective behaviors.

\section{Supplementary Information}

The online version contains supplementary material available at https://doi. org/10.1186/s12889-020-09892-y.

Additional file 1: Questionnaire. Questionnaire developed for this research

Additional file 2: Table S1. Constructs and items measured in the PLS SEM. Table S2. Psychometric Table of Measurements. Fig. S1. Results of SEM. Table S3. Path coefficients tested in the SEM

Additional file 3: Table S4. Results of linear regression models

\section{Abbreviations}

COVID-19: Coronavirus disease 2019; WHO: World health Organization; SARSCoV-2: Severe acute respiratory syndrome coronavirus 2; KAP: Knowledge, attitude and practices; SARF: Social amplification of risk framework; SEM: Structural equation model

\section{Acknowledgements}

Not Applicable.

\section{Authors' contributions}

$\mathrm{YH}$ and LG took overall responsibility for the study design, coordination of the survey, development of the analysis framework and writing of the manuscript. LN, JN, XB participated in the design of the research, conducted the survey and data analyses and drafted the manuscript. CY, QW, AL participated in the design of the research, revised suggestion of manuscript. $\mathrm{ZL}, \mathrm{NN}, \mathrm{LL}$ participated in the literature review and data collection. $\mathrm{CL}$ supervised the data analyses, interpreted the results and revised the manuscript. LN, JN, XB contributed equally. All authors read and approved the final manuscript.

\section{Funding}

This study was funded by the National Natural Scientific Fund of China (71673072, 72042001). Funding body had no influence on study design, data collection, data analysis, data interpretation or writing the manuscript.

\section{Availability of data and materials}

The datasets generated and analyzed during the current study are not publicly available because the datasets are currently used for another project, but are available from the corresponding author on reasonable request.

Ethics approval and consent to participate

Ethics approval for the study protocol was obtained from the Ethics Committee of Harbin Medical University. IRB code is HMUIRB20200004. Informed consent was obtained from all participants through online responses before the start of the survey. The Ethics Committee of Harbin Medical University approved the procedure for obtaining informed consent.

\section{Consent for publication}

Not applicable.

Competing interests

The authors declare no conflict of interest. 


\section{Author details}

${ }^{1}$ School of Health Management, Harbin Medical University, Harbin, China. ${ }^{2}$ Harbin Center for Disease Control and Prevention, Harbin, China. ${ }^{3}$ School of Education Science, Harbin Normal University, Harbin, China. ${ }^{4}$ School of Psychology and Public Health, La Trobe University, Melbourne, VIC 3086, Australia.

Received: 28 July 2020 Accepted: 15 November 2020

\section{Published online: 23 November 2020}

\section{References}

1. Ferguson NM. Impact of non-pharmaceutical interventions (NPIs) to reduce COVID- 19 mortality and healthcare demand. 2020. doi:https://doi.org/10. 25561/77482.

2. WHO. Rolling updates on coronavirus disease (COVID-19), https://www.who. int/emergencies/diseases/novel-coronavirus-2019/events-as-they-happen, (accessed 30 Jan 2020) 2020.

3. Jang WM, Cho S, Jang DH, Kim U, Jung H, Lee JY, et al. Preventive behavioral responses to the 2015 middle east respiratory syndrome coronavirus outbreak in Korea. Int J Environ Res Public Health. 2019;16(12):2161.

4. Everett JA, Colombatto C, Chituc V, et al. The effectiveness of moral messages on public health behavioral intentions during the COVID-19 pandemic. PsyArXiv. 2020. https://doi.org/10.31234/osf.io/9yqs8.

5. Bish A, Michie S. Demographic and attitudinal determinants of protective behaviours during a pandemic: a review. Br J Health Psychol. 2010;15(Pt 4): 797-824.

6. Wang C, Pan R, Wan X, Tan Y, Xu L, Ho CS, et al. Immediate psychological responses and associated factors during the initial stage of the 2019 coronavirus disease (COVID-19) epidemic among the general population in China. Int J Environ Res Public Health. 2020;17(5):1729.

7. Wang C, Pan R, Wan X, et al. A longitudinal study on the mental health of general population during the COVID-19 epidemic in China. Brain Behav Immun. 2020;87:40-8.

8. Tee ML, Tee CA, Anlacan JP, Aligam KJG, Reyes PWC, Kuruchittham V, et al. Psychological impact of COVID-19 pandemic in the Philippines. J Affect Disord. 2020;277:379-91.

9. Seo M. Amplifying panic and facilitating prevention multifaceted effects of traditional and social media use during the 2015 MERS crisis in South Korea. J Mass Commun Q. 2019. https://doi.org/10.1177/1077699019857693.

10. WHO. Managing Epidemics, Key Facts About Major Deadly Diseases. 2018. https://apps.who.int/iris/handle/10665/272442.

11. Howard J, Huang A, Li Z, et al. Face masks against COVID-19: an evidence review. Preprints. 2020. doi:https://doi.org/10.20944/preprints202004.0203.v1.

12. Ahmed F, Zviedrite N, Uzicanin A. Effectiveness of workplace social distancing measures in reducing influenza transmission: a systematic review. BMC Public Health. 2018;18(1):518.

13. Fung IC, Cairncross S. Effectiveness of handwashing in preventing SARS: a review. Tropical Med Int Health. 2006;11(11):1749-58.

14. Lau H, Khosrawipour $\mathrm{V}$, Kocbach $\mathrm{P}$, et al. The positive impact of lockdown in Wuhan on containing the COVID-19 outbreak in China. J Travel Med. 2020; 27(3):taaa037.

15. Kim Y, Zhong $W$, Jehn M, Walsh L. Public risk perceptions and preventive behaviors during the 2009 H1N1 influenza pandemic. Disaster Med Public Health Prep. 2015;9(2):145-54.

16. Kim CW, Song HR. Structural relationships among Public's risk characteristics, trust, risk perception and preventive behavioral intention: the case of MERS in Korea. Crisisonomy. 2017;13(6):85-95.

17. Kasperson RE, Renn O, Slovic P, et al. The social amplification of risk: a conceptual framework. Risk Anal. 1988;8(2):177-87.

18. Launiala A. How much can a KAP survey tell us about people's knowledge, attitudes and practices? Some observations from medical anthropology research on malaria in pregnancy in Malawi. Anthropol Matters. 2009;11(1): $1-13$.

19. WHO. Coronavirus disease (COVID-19) advice for the public. https://www. who.int/emergencies/diseases/novel-coronavirus-2019/advice-for-public. 2020.

20. Walpole HD, Wilson RS. Extending a broadly applicable measure of risk perception: the case for susceptibility. J Risk Res. 2020:1-13.

21. Elledge $B L$, Brand $M$, Regens $J$, Boatright DT. Implications of public understanding of avian influenza for fostering effective risk communication. Health Promot Pract. 2008;9(4 Suppl):54S-9S.
22. Zhong B. Knowledge, attitudes, and practices towards COVID-19 among Chinese residents during the rapid rise period of the COVID-19 outbreak: a quick online cross-sectional survey. Int J Biol Sci. 2020;16(10):1745-52.

23. Slovic P. Perception of risk. Science. 1987;236:280-5.

24. Williams L, Regagliolo A, Rasmussen S. Predicting psychological responses to influenza a, H1N1 ("swine flu"): the role of illness perceptions. Psychol Health Med. 2012;17(4):383-91.

25. Tenkorang EY. Effect of knowledge and perceptions of risks on Ebolapreventive behaviours in Ghana. Int Health. 2018;10(3):202-10.

26. Wise T. Changes in risk perception and protective behavior during the first week of the COVID-19 pandemic in the United States. PsyArXiv. 2020. https://doi.org/10.31234/osf.io/dz428.

27. Qian M. Psychological responses, behavioral changes and public perceptions during the early phase of the COVID-19 outbreak in China: a population based cross-sectional survey. medRxiv. 2020. https://doi.org/10. 1101/2020.02.18.20024448.

28. Kasperson REGD, Tuler S. Social distrust as a factor in siting hazardous facilities and communicating risks. J Soc Issues. 1992;8(4):161-87.

29. Ya-jun D. Establishment and evaluation on reliability and validity of public risk perception scale for public health emergencies. Chin J Public Health. 2018. https://doi.org/10.11847/zgggws1119744.

30. Ahorsu DK, Lin C, Imani V, Saffari M, Griffiths MD, Pakpour AH. The fear of COVID-19 scale: development and initial validation. Int J Ment Health Addict. 2020;27:1-9.

31. Li J. Self-control moderates the association between perceived severity of the coronavirus disease 2019 (COVID-19) and mental health problems among the Chinese public. Int J Environ Res Public Health. 2020;17(13):4820.

32. Harper CA. Functional fear predicts public health compliance in the COVID19 pandemic. Int J Ment Health Addict. 2020:1-14. https://doi.org/10.1007/ s1 1469-020-00281-5.

33. Irving LJ. Effects of fear arousal on attitude change: recent developments in theory and experimental research. Adv Exp Soc Psychol. 1967;3:166-224.

34. Frijda NH. The emotions: Studies in emotion and social interaction. 1986.

35. Yang JZ. Who is afraid of the Ebola outbreak? The influence of discrete emotions on risk perception. J Risk Res. 2018;21(7):834-53.

36. Balkhy HH, Abolfotouh MA, Al-Hathlool RH, Al-Jumah MA. Awareness, attitudes, and practices related to the swine influenza pandemic among the Saudi public. BMC Infect Dis. 2010;10:42

37. Ho SS. The knowledge gap hypothesis in Singapore: the roles of socioeconomic status, mass media, and interpersonal discussion on public knowledge of the H1N1 flu pandemic. Mass Commun Soci. 2012;15:695717.

38. Zhang L, Kong $Y$, Chang H. Media use and health behavior in H1N1 flu crisis: the mediating role of perceived knowledge and fear. Atl J Commun. 2015;23:67-80.

39. Gao J, Zheng P, Jia Y, et al. Mental health problems and social media exposure during COVID-19 outbreak. PLoS One. 2020;15(4):e0231924.

40. Kellens W. T. Terpstra aPDM. Perception and communication of flood risks: a systematic review of empirical research. Risk Anal. 2013;33(1):24-49.

41. Dashraath P, Jeslyn WJL, Karen LMX, et al. Coronavirus disease 2019 (COVID19) pandemic and pregnancy. Am J Obstet Gynecol. 2020;222(6):521-31.

42. Hair JF Jr, Sarstedt M, Hopkins L, Kuppelwieser VG. Partial least squares structural equation modeling (PLS-SEM): an emerging tool in business research. Eur Bus Rev. 2014;26(2):106-21.

43. Lau JT, Yang $X$, Tsui H, Kim JH. Monitoring community responses to the SARS epidemic in Hong Kong: from day 10 to day 62. J Epidemiol Community Health. 2003;57(11):864-70.

44. Setbon MPML, Létroublon CCA, Raude J. The public's preventive strategies in response to the pandemic influenza a/H1N1 in France: distribution and determinants. Prev Med. 2011;52(2):178-81.

45. Kwok KO. Community responses during the early phase of the COVID-19 epidemic in Hong Kong: risk perception, information exposure and preventive measures. Emerg Infect Dis. 2020;26(7):1575-9.

46. Bults M, Beaujean DJ, de Zwart O, et al. Perceived risk, anxiety, and behavioural responses of the general public during the early phase of the influenza a (H1N1) pandemic in the Netherlands: results of three consecutive online surveys. BMC Public Health. 2011;11:2

47. Choi JS, Kim JS. Factors influencing preventive behavior against Middle East respiratory syndrome-coronavirus among nursing students in South Korea. Nurse Educ Today. 2016;40:168-72. 
48. Cho JLJ. An integrated model of risk and risk -reducing trategies. J Bus Res. 2006;59(1):112-20.

49. Wachinger G, Renn O, Begg C, Kuhlicke C. The risk perception paradox-implications for governance and communication of natural hazards. Risk Anal. 2013;33(6):1049-65.

50. Leung GM, Lam TH, Ho LM, Ho SY, Chan B, Wong I, et al. The impact of community psychological responses on outbreak control for severe acute respiratory syndrome in Hong Kong. J Epidemiol Community Health. 2003; 57(11):857-63.

51. Zeng J, Jiang M, Yuan M. Environmental risk perception, risk culture, and pro-environmental behavior. Int J Environ Res Public Health. 2020;17(5):1750,

52. Janiszewski C. Pre-attentive mere exposure effects. J Consum Res. 1993; 20(3):376-92.

53. Slovic P. Trust, emotion, sex, politics, and science: surveying the riskassessment battlefield. Risk Anal. 1999;19(4):689-701.

54. Menon KU, Goh KT. Transparency and trust: risk communications and the Singapore experience in managing SARS. J Commun Manag. 2005;9(4):375-83.

55. Le HT, Nguyen DN, Beydoun AS, Le XTT, Nguyen TT, Pham QT, et al. Demand for health information on COVID-19 among Vietnamese. Int J Environ Res Public Health. 2020;17(12):4377.

56. Tran BX, Dang AK, Thai PK, Le HT, Le XTT, Do TTT, et al. Coverage of health information by different sources in communities: implication for COVID-19 epidemic response. Int J Environ Res Public Health. 2020;17(10):3577.

57. Wray RJ, Becker SM, Henderson N, et al. Communicating with the public about emerging health threats: lessons from the pre-event message development project. Am J Public Health. 2008;98(12):2214-22.

58. Barr M, Raphael B, Taylor M, et al. Pandemic influenza in Australia: using telephone surveys to measure perceptions of threat and willingness to comply. BMC Infect Dis. 2008;8:117.

59. Zettler I. Individual differences in accepting personal restrictions to fight the COVID-19 pandemic: Results from a Danish adult sample. PsyArXiv. 2020. https://doi.org/10.31234/osf.io/pkm2a.

\section{Publisher's Note}

Springer Nature remains neutral with regard to jurisdictional claims in published maps and institutional affiliations.

Ready to submit your research? Choose BMC and benefit from:

- fast, convenient online submission

- thorough peer review by experienced researchers in your field

- rapid publication on acceptance

- support for research data, including large and complex data types

- gold Open Access which fosters wider collaboration and increased citations

- maximum visibility for your research: over $100 \mathrm{M}$ website views per year

At $\mathrm{BMC}$, research is always in progress.

Learn more biomedcentral.com/submissions 